\section{Factors associated with topographic changes of the optic nerve head induced by acute intraocular pressure reduction in glaucoma patients}

TS Prata ${ }^{1,2}$, VC Lima ${ }^{1,2}$, CG Vasconcelos de Moraes², LM Guedes', FP Magalhães', SH Teixeira' ${ }^{1}$, R Ritch $^{2,3}$ and A Paranhos $\mathrm{Jr}^{1}$
${ }^{1}$ Department of Ophthalmology, Federal University of São Paulo, São Paulo, Brazil

${ }^{2}$ Einhorn Clinical Research Center, The New York Eye and Ear Infirmary, New York, NY, USA

${ }^{3}$ New York Medical College, Valhalla, NY, USA

Correspondence: TS Prata, Department of

Ophthalmology, Federal University of São Paulo, Rua Botucatu, São Paulo 820, Brazil.

Tel: + 55115085 2010;

Fax: + 551150852020 .

E-mail: tiagoprata@ig.com.br

Received: 5 October 2009 Accepted in revised form: 15 October 2010;

Published online: 3

December 2010

Presentation: This study was presented in part at the Annual Meeting of the Association for Research in Vision and Ophthalmology, Fort Lauderdale, FL, May 2009 
increase in the neural rim area and a decrease in the cup size, probably due to anterior shifting of the LC. ${ }^{7-12}$ The inverse mechanism was observed after IOP elevation. ${ }^{13}$

Susceptibility to glaucomatous damage varies among patients and seems to be related to several individual ocular and systemic characteristics. Although some factors such as age $\mathrm{e}^{1,14-16}$ and central corneal thickness (CCT) are better established, ${ }^{1,14,16}$ others such as corneal hysteresis $(\mathrm{CH})^{17}$ and diabetes mellitus (DM) ${ }^{11,18-21}$ remain controversial.

The mechanical damage in glaucoma involves the biomechanical properties of the $\mathrm{ONH}$, mainly related to the stiffness of the LC, scleral canal wall, and peripapillary sclera, as demonstrated in studies based on ONH modelling..$^{6,22-26}$ Previous studies have suggested that systemic and ocular factors, such as ageing, ${ }^{27-29}$ chronically elevated IOP, ${ }^{30-32}$ level of glaucomatous damage, ${ }^{1,17,33}$ and disc size (scleral canal diameter), ${ }^{34}$ could influence the susceptibility of an individual $\mathrm{ONH}$ to a given level of IOP. More recently, it has been suggested that other factors could be either directly or indirectly related to $\mathrm{ONH}$ response to pressure-induced damage, such as corneal parameters (both CCT and $\mathrm{CH})^{13,35-37}$ and diabetes. ${ }^{1,37,38}$ In glaucoma management, it is important to identify which factors are significantly related to an individual response to pressure-induced damage. Once these factors are known, it is possible to identify patients at a greater risk for disease progression and to set a patient's target IOP. Therefore, we designed this clinical study to investigate possible factors associated with pressure-induced changes in $\mathrm{ONH}$ topography in patients with primary open-angle glaucoma (POAG).

\section{Patients and methods}

This prospective protocol adhered to the tenets of the Declaration of Helsinki and was approved by The Ethics Committee of The Federal University of São Paulo. In addition, written informed consent was obtained from all subjects.

\section{Patients}

We prospectively enrolled consecutive untreated newly diagnosed POAG patients, with and without type II DM, from the general clinic of the Ophthalmology Department of the Federal University of São Paulo. Patients who met our inclusion criteria were promptly directed to the glaucoma clinic, where a complete ophthalmological examination was conducted. Exclusion criteria were systemic collagen diseases, ${ }^{39}$ history of using oral or topical steroids, spherical equivalent $> \pm 4.0 \mathrm{D}$, previous ocular surgery or trauma, secondary glaucomas, and any ocular disease other than glaucoma (including diabetic retinopathy). All diabetic patients were under medical (insulin or oral hypoglycaemic) treatment. POAG was defined as characteristic GON and visual field loss, with IOP $>21 \mathrm{~mm} \mathrm{Hg}$ on two separate occasions and a widely open angle.

Typical GON was defined as a vertical cup-to-disc ratio $>0.5$, asymmetry of the cup-to-disc ratio $\geq 0.2$ between the eyes, the presence of localized RNFL defects, and/or neuroretinal rim defects in the absence of any other abnormalities that could explain such findings.

A glaucomatous visual field defect in the standard automated perimetry (Humphrey SITA - Standard 24-2, Carl Zeiss Meditec, Dublin, CA, USA) was defined as three or more points in clusters with a probability of $<5 \%$ (excluding those on the edge of the field or directly above and below the blind spot) on the pattern deviation plot, a pattern SD index with a probability of $<5 \%$, or a glaucoma hemifield test with results outside the normal limits.

\section{Procedures}

Baseline data included systemic (age, gender, selfdescribed race, and diabetes diagnosis) and ocular (CCT and $\mathrm{CH}$ ) factors. The ocular response analyzer (ORA; Reichert Inc., Depew, NY, USA) was used to assess $\mathrm{CH}$ values. The ORA is a non-contact tonometer that measures IOP calibrated to Goldmann and corneal-compensated IOP, taking into account corneal biomechanical properties. It also measures other parameters, including $\mathrm{CH}$, which is an estimate of the viscoelastic (time-dependant) material properties of the cornea. ${ }^{40,41} \mathrm{CH}$ is correlated with CCT, and seems not to be associated with refractive error or axial length. ${ }^{42,43} \mathrm{CH}$ as measured by the ORA is described in greater detail elsewhere. ${ }^{40,41,44}$ For this study, four measurements were obtained for each eye and the average was considered as the final value for analysis. Readings from the ORA required consistent and smooth raw signal morphology (clean, sharp, well-defined raw signal peaks, with repeatable characteristics for multiple measurements). If the measurements differed by $>2 \mathrm{~mm} \mathrm{Hg}$, an additional measurement was taken and the two extreme values were excluded from the analysis. ${ }^{44}$

Confocal scanning laser ophthalmoscopy using the Heidelberg retina tomograph III (HRT; Heidelberg Engineering, Heidelberg, Germany) and Goldmann applanation tonometry were performed before and $1 \mathrm{~h}$ after pharmacological IOP reduction (topical timolol maleate $0.5 \%$ + brimonidine tartrate $0.2 \%$, topical bimatoprost $0.03 \%$, and oral acetazolamide $500 \mathrm{mg}$ ). All patients were refracted before the first HRT examination, and whenever the cylinder was $\geq 1.00 \mathrm{D}$, correction for 
corneal astigmatism was performed. The following stereometric parameters were investigated: rim area, cup area, rim volume, cup volume, and mean cup depth. The mean of three measurements was used for all tests, and quality control of the scans was set to $<30 \mu \mathrm{m}$ SD. Three patients were excluded from the analysis because of poor quality scans. The same examiners performed all the HRT (LMG), tonometry, and ORA (TSP) examinations, and both were masked for patient's data. All tests were performed on the same day. After the last test, glaucoma treatment was initiated, confirmatory/ancillary examinations were scheduled, and patients were followed up regularly.

\section{Statistical analysis}

Descriptive analysis was used to present demographic and clinical data. D'Agostino-Pearson's test was performed to determine whether the HRT data had a normal distribution. As it rejected normality $(P<0.05)$, we used a non-parametric test (Wilcoxon's signed-rank test) to compare baseline and post-IOP reduction values for each HRT parameter. The ONH parameter chosen for sample size calculation was cup area. Considering a mean difference in cup area values before and after IOP reduction of $0.05 \mathrm{~mm}^{2}$ and a mean $\mathrm{SD}$ of the differences of $0.1 \mathrm{~mm}^{2}$, for an $\alpha$-error of 0.05 , it would require 37 patients ( 1 eye per patient) to reach a statistical power of $80 \%$. After assessing changes in each $\mathrm{ONH}$ topographic parameter, those that changed significantly were correlated with patient's systemic (age, race, and presence of diabetes) and ocular characteristics (disc area, cup-to-disc ratio, $\mathrm{CCT}$, and $\mathrm{CH}$ ) using multiple regression analysis. In the regression analysis, the presence of diabetes was taken as ' 1 ' and the absence of diabetes as ' 0 '. First, each variable was analyzed separately, controlling for baseline IOP and amount of IOP reduction. All variables with a statistically significant result ( $P$-value was adjusted for multiple comparisons using Bonferroni's correction) were then included in the multivariable model. Computerized analysis was performed using MedCalc software (MedCalc Inc., Mariakerke, Belgium).

\section{Results}

A total of 42 POAG patients were included in the analysis (18 with and 24 without type II DM). Baseline demographics and clinical data are provided in Table 1. The mean age was $66.7 \pm 11.8$ years, and most patients were women $(n=29)$ and White $(n=24)$. After a mean IOP reduction of $47.3 \pm 11.9 \%(13.3 \pm 6.5 \mathrm{~mm} \mathrm{Hg})$, the majority of the eyes had intuitive HRT parameters changes (inward movement) in the five HRT parameters
Table 1 Baseline characteristics of primary open-angle glaucoma patients $^{\mathrm{a}}$

\begin{tabular}{lc}
\hline Variables & Patients $(\mathrm{n}=42)$ \\
\hline Age (years) & $66.7 \pm 11.8$ \\
Gender (female/male) & $29 / 13$ \\
Race (White/African descent/mixed) & $24 / 10 / 8$ \\
Type II diabetes diagnosis & 18 out of 42 \\
Baseline intraocular pressure $(\mathrm{mm} \mathrm{Hg})$ & $27.9 \pm 8.1$ \\
Intraocular pressure reduction $(\mathrm{mm} \mathrm{Hg})$ & $13.3 \pm 6.5$ \\
Intraocular pressure reduction $(\%)$ & $47.3 \pm 11.9$ \\
Central cornea thickness $(\mu \mathrm{m})$ & $541.8 \pm 34.5$ \\
Corneal hysteresis (mm Hg) & $8.1 \pm 1.8$ \\
HRT_disc area (mm $\left.{ }^{2}\right)$ & $2.43 \pm 0.5$ \\
HRT_-linear cup-to-disc ratio & $0.57 \pm 0.16$ \\
HRT-mean cup depth (mm) & $0.31 \pm 0.1$ \\
Fundoscopy-cup-to-disc ratio & $0.70 \pm 0.11$ \\
Visual field mean deviation $(\mathrm{dB})$ & $-5.7 \pm 5.2$
\end{tabular}

Abbreviation: HRT, Heidelberg retina tomograph.

${ }^{a}$ Data are given as mean \pm SD whenever indicated.

Table 2 Changes in optic nerve head topography after intraocular pressure reduction in primary open-angle glaucoma patients $^{\mathrm{a}}$

\begin{tabular}{lcccc}
\hline $\begin{array}{l}\text { HRT } \\
\text { parameters }\end{array}$ & $\begin{array}{c}\text { Mean } \\
\text { change }\end{array}$ & $95 \%$ CI & $\begin{array}{c}\text { Eyes } \\
\text { with intuitive } \\
\text { changes }\end{array}$ & P-value \\
\hline $\begin{array}{l}\text { Rim area } \\
\left(\mathrm{mm}^{2}\right)\end{array}$ & 0.044 & $0.014-0.074$ & $32(76 \%)$ & 0.003 \\
$\begin{array}{l}\text { Rim volume } \\
\left(\mathrm{mm}^{3}\right)\end{array}$ & 0.026 & $0.011-0.041$ & $30(71 \%)$ & 0.001 \\
$\begin{array}{l}\text { Cup area } \\
\left(\mathrm{mm}^{2}\right)\end{array}$ & -0.046 & -0.012 to -0.079 & $32(76 \%)$ & 0.008 \\
$\begin{array}{l}\text { Cup volume } \\
\left(\mathrm{mm}^{3}\right)\end{array}$ & -0.018 & -0.004 to -0.030 & $30(71 \%)$ & 0.009 \\
$\begin{array}{l}\text { Mean CD } \\
(\mathrm{mm})\end{array}$ & & $0.0005-0.003$ & $24(57 \%)$ & 0.798 \\
\hline
\end{tabular}

Abbreviations: CD, cup depth; HRT, Heidelberg retina tomograph. ${ }^{a}$ Difference between post-IOP reduction and baseline HRT values.

${ }^{\mathrm{b}}$ An intuitive HRT parameter change after intraocular pressure reduction was considered when rim area and rim volume increased, and when cup area, cup volume, and mean cup depth decreased.

'Wilcoxon's signed-rank test (data were not normally distributed based on D'Agostino-Pearson's test).

evaluated (Table 2). Significant mean changes were observed in cup area, cup volume, rim area, and rim volume $(P<0.01)$, but not in mean cup depth $(P=0.80)$.

With regard to the correlation between HRT parameters that changed significantly and patient's characteristics (Table 3), we chose only one volumetric (cup volume) and one bi-dimensional (cup area) HRT parameter as dependent variables, as changes in cup and rim are strongly correlated. Multiple regression analysis (controlling for baseline IOP and magnitude of IOP 
Table 3 Factors associated with changes in optic nerve head topography after intraocular pressure reduction

\begin{tabular}{|c|c|c|c|c|c|c|}
\hline \multirow[t]{2}{*}{ Variables } & \multicolumn{3}{|c|}{ Cup area changes } & \multicolumn{3}{|c|}{ Cup volume changes } \\
\hline & $\mathrm{R}^{2}$ & P-value ${ }^{\mathrm{a}}$ & P-value ${ }^{\mathrm{b}}$ & $\mathrm{R}^{2}$ & P-value ${ }^{\mathrm{a}}$ & P-value ${ }^{\mathrm{b}}$ \\
\hline Age (years) & 0.01 & 0.751 & & 0.01 & 0.583 & \\
\hline $\begin{array}{l}\text { Race (African } \\
\text { descent) }\end{array}$ & 0.03 & 0.273 & & 0.01 & 0.662 & \\
\hline $\begin{array}{l}\text { Presence } \\
\text { of diabetes }\end{array}$ & 0.34 & $<0.001$ & $<0.001$ & 0.21 & $<0.001$ & $<0.001$ \\
\hline Cup-to-disc ratio & 0.08 & 0.042 & & 0.30 & $<0.001$ & $<0.001$ \\
\hline Disc area $\left(\mathrm{mm}^{2}\right)$ & 0.06 & 0.121 & & 0.01 & 0.792 & \\
\hline CCT $(\mu \mathrm{m})$ & 0.01 & 0.508 & & 0.01 & 0.722 & \\
\hline $\mathrm{CH}(\mathrm{mm} \mathrm{Hg})$ & 0.17 & 0.005 & 0.121 & 0.16 & 0.009 & \\
\hline
\end{tabular}

Abbreviations: $\mathrm{CCT}$, central corneal thickness; $\mathrm{CH}$, corneal hysteresis; IOP, intraocular pressure.

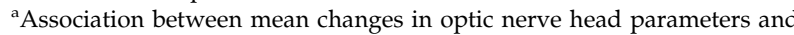
each patient's characteristic, controlling for baseline IOP and magnitude of IOP reduction (\%). Statistical significance was set at $P<0.007$ (Bonferroni's correction).

${ }^{b}$ Multivariable model (only variables with a $P$-value $<0.007$ were entered).

reduction) showed that $\mathrm{CH}\left(r^{2}=0.17, P<0.01\right)$ and diabetes diagnosis $\left(r^{2} \geq 0.21, P<0.01\right)$ were negatively correlated with the magnitude of changes in $\mathrm{ONH}$ parameters, whereas the cup-to-disc ratio was positively correlated $\left(r^{2}=0.30, P<0.01\right)$. Age, race, disc area, and CCT were not significant in this model $(P \geq 0.12)$. Including all significant factors in a multivariable model, only the presence of diabetes remained significantly associated with all $\mathrm{ONH}$ parameters evaluated $(P<0.01)$. No statistically significant interactions were found between our independent variables (all $P$-values for interaction terms $\geq 0.22$ ).

\section{Discussion}

Our results suggest that a lower $\mathrm{CH}$, larger cup-to-disc ratio, and the absence of diabetes are statistically significantly related to greater $\mathrm{ONH}$ topographic changes after acute IOP reduction. To the best of our knowledge, this is the first study to report on both systemic and ocular factors associated with topographic changes in the $\mathrm{ONH}$ after acute IOP reduction in patients with POAG.

Few studies have addressed the association between corneal parameters and $\mathrm{ONH}$ topographic changes after IOP variation (increase or decrease) in glaucomatous patients. ${ }^{13,35}$ We found that a lower $\mathrm{CH}$ (but not CCT) was correlated with greater $\mathrm{ONH}$ changes after IOP reduction (univariate analysis results). When other covariates were considered, this correlation lost its significance. Comparing $\mathrm{CH}$ values in POAG patients with and without acquired pits of the $\mathrm{ONH}$, Bochmann et $\mathrm{al}^{36}$ documented lower $\mathrm{CH}$ values in those with acquired pits. Finally, regarding other corneal parameters, Lesk et $a l^{35}$ observed that patients with thinner corneas have greater $\mathrm{ONH}$ topographic changes after IOP reduction than do patients with thicker corneas. $\mathrm{CH}$, which is known to be positively correlated with CCT values, ${ }^{42}$ was not assessed in that study. On the other hand, Wells $e t$ al $^{13}$ correlated higher $\mathrm{CH}$ values (but not CCT) with greater changes in ONH topography after IOP increase. In this study, we analyzed cupping reversal (IOP reduction), which was the methodology used in the majority of previous studies, ${ }^{7-12}$ in a study population composed of POAG patients without intraocular surgery. Wells et $a l^{13}$ evaluated cupping distension (increasing IOP to an average of $64 \mathrm{~mm} \mathrm{Hg}$ ) in different types of glaucoma, some with intraocular surgery and with a lower mean age than our group. We believe that there are significant differences in study design and population between these two studies, and that further research is necessary to clarify the relationship between $\mathrm{CH}$ and $\mathrm{ONH}$ topographic changes after IOP variation (reduction or increase).

Evaluating POAG patients with moderate cupping (mean cup-to-disc ratio on fundoscopy, $0.70 \pm 0.11$ (95\% CI, 0.66-0.73)), we found a statistically significant correlation between the cup-to-disc ratio (but not disc size) and $\mathrm{ONH}$ topographic changes after IOP reduction. Patients with larger cupping had greater $\mathrm{ONH}$ changes. There are no previous data reported on this subject. Although the correlation we found seems reasonable, the way the ONH responds to IOP variation is still not fully understood ${ }^{45}$ and seems to depend on both laminar and scleral canal deformation. ${ }^{46}$ In addition, this correlation was not statistically significant for both $\mathrm{ONH}$ parameters (cup area and volume) in the multivariable analysis. We could also have found different results if our sample was composed of patients with more advanced damage. Chronically elevated IOP and advanced disease stage seems to produce progressive changes in the $\mathrm{ONH}$, including axonal and non-axonal effects (extracellular matrix and astrocytes), possibly resulting in a stiffer and less deformable structure. ${ }^{30-32,47,48}$

Among systemic factors evaluated in our study, only diabetes was significantly associated with pressureinduced topographic changes in the $\mathrm{ONH}$. The presence of diabetes in glaucoma patients was related to a smaller magnitude of changes in $\mathrm{ONH}$ topographic parameters after IOP reduction, even after adjusting for other covariates. Differently from other factors evaluated in this study, diabetes correlated not only with bi-dimensional but also with volumetric cup parameters, which involves a complex interaction between scleral (lateral displacement of $\mathrm{ONH}$ tissues) and laminar (vertical displacement of the LC) changes. Although no previous study has evaluated this correlation, recent reports addressing directly or indirectly the association 
between diabetes and glaucoma suggested that the former may influence an individual susceptibility to glaucomatous damage. ${ }^{37,38}$ In a recent editorial, Quigley ${ }^{38}$ commented on the presence of diabetes as a possible protective factor for mechanical damage in glaucoma and questioned why we cannot believe our own data. In a previous report, results of the Ocular Hypertension Treatment Study ${ }^{1}$ suggested that there may be some protective effect of diabetes on the conversion from ocular hypertension to POAG. Although this finding has been much debated, our results may support it, as the presence of diabetes was independently associated with a smaller magnitude of pressure-induced cup changes in our study. The eyes of diabetic patients have more collagen cross-linking through glycation process, resulting in increased corneal stiffness and higher $\mathrm{CH}$ values. ${ }^{37,49-51}$ The same processes that lead to increased corneal stiffness in diabetes may happen in other eye structures containing collagen fibres. Results from the study by Lesk et $a l^{35}$ have suggested an association between corneal thickness and laminar stiffness. The eyes with thinner corneas would have a more compliant LC (reduced stiffness), thus allowing greater laminar displacement and increased axonal injury after IOP fluctuations. Corroborating these thoughts, collagen cross-linking was found to reduce pressure-induced laminar strain levels in porcine eyes in a recent study. ${ }^{52}$ We therefore hypothesized that diabetic eyes not only have an increased corneal stiffness as previously documented but also have an increased laminar stiffness, which would provide protection against mechanical damage in glaucoma. However, it is important to re-emphasize that pressure-induced changes on $\mathrm{ONH}$ connective tissues involve not only laminar deformation. It also involves regional thinning, stretching, and deformation of both the LC and the peripapillary sclera, which were not evaluated in this study. In addition, an individual susceptibility to glaucoma is still not fully understood and axons are damaged by effects of IOP-related stress through various mechanisms. ${ }^{26,33,53-59}$ Therefore, we believe that any conclusion whether increased tissue stiffness is a risk or a protective factor for glaucomatous injury would be a premature assumption.

There are important facts that should be considered while interpreting our results. First, age did not correlate with $\mathrm{ONH}$ response to acute IOP reduction in our study. However, as it has been previously demonstrated that age can alter the mechanical integrity of the $\mathrm{LC}_{,}^{27,28} \mathrm{a}$ study with a wider age range could possibly detect a significant correlation. Second, although HRT provides reproducible objective and quantitative topographic measurements, ${ }^{60}$ it has been suggested that a significant proportion of the change measured by this technology may be in the pre-laminar tissues rather than in the lamina. ${ }^{23,25}$ In addition, the fact that the HRT parameters that changed significantly were not depth measurements (such as mean cup depth), suggests that these changes could be related to neural tissue properties rather than laminar properties. Third, $\mathrm{CH}$ is at present a manifestation of some aspect of the material properties of the cornea, but what those properties are remains unclear. Fourth, this study did not evaluate patients with diabetic retinopathy. Therefore, our results only apply to diabetic patients without retinopathy. As retinopathy itself could lead to different results compared with those we found, the influence of diabetic retinopathy on $\mathrm{ONH}$ response to IOP variation (reduction) requires further investigation. Finally, all factors significantly associated with topographic changes of $\mathrm{ONH}$ parameters had a weak coefficient of determination ( $r^{2}$ range, 0.17-0.34). Therefore, these associations accounted for only part of the $\mathrm{ONH}$ changes observed in these patients. Although statistically significant, their clinical relevance is still to be determined as these associations do not explain entirely an individual (ONH) response to IOP variation (reduction in our study). These findings suggest that other factors not evaluated in this study are implicated in the ONH susceptibility to IOP.

In conclusion, our findings suggest that different systemic and ocular factors, such as diabetes, $\mathrm{CH}$, and the relative size of the cup, seem to be associated with the magnitude of changes in $\mathrm{ONH}$ topography after acute IOP reduction in POAG patients. Whether these observations have implications in the understanding of glaucoma pathophysiology requires further investigation.

\section{Summary}

What was known before

- Acute intraocular pressure (IOP) reduction induces morphological changes in the optic nerve head-there is an individual susceptibility to these changes - these changes seem to be related to different ocular and systemic factors (only corneal properties have been studied).

\section{What this study adds}

- This is the first study to investigate both systemic and ocular factors associated with morphological changes in the optic nerve head after acute IOP reduction in primary open-angle glaucoma patients - our findings suggest that factors, such as diabetes, corneal hysteresis, and the relative size of the cup, seem to be associated with the magnitude of changes in $\mathrm{ONH}$ morphology after acute IOP reduction.

\section{Conflict of interest}

The authors declare no conflict of interest. 


\section{Acknowledgements}

We thank Dr Claude F. Burgoyne for his careful reading of our manuscript and his thoughtful comments. Antiglaucoma medications used in this study were provided in part by Allergan Laboratories.

\section{References}

1 Gordon MO, Beiser JA, Brandt JD, Heuer DK, Higginbotham EJ, Johnson CA et al. The Ocular Hypertension Treatment Study: baseline factors that predict the onset of primary open-angle glaucoma. Arch Ophthalmol 2002; 120: 714-720.

2 Weinreb RN, Khaw PT. Primary open-angle glaucoma. Lancet 2004; 363: 1711-1720.

3 Quigley HA, Guy J, Anderson DR. Blockade of rapid axonal transport. Effect of intraocular pressure elevation in primate optic nerve. Arch Ophthalmol 1979; 97: 525-531.

4 Quigley HA, Addicks EM, Green R, Maumenee AE. Optic nerve damage in human glaucoma. II. The site of injury and susceptibility to damage. Arch Ophthalmol 1981; 99: 635-649.

5 Langham ME. The temporal relation between intraocular pressure and loss of vision in chronic simple glaucoma. Glaucoma 1980; 2: 427-435.

6 Burgoyne CF, Downs JC, Bellezza AJ, Suh JK, Hart RT. The optic nerve head as a biomechanical structure: a new paradigm for understanding the role of IOP-related stress and strain in the pathophysiology of glaucomatous optic nerve head damage. Prog Retin Eye Res 2005; 24 : 39-73.

7 Lesk MR, Spaeth GL, Azuara-Blanco A, Araujo SV, Katz LJ, Terebuh AK et al. Reversal of optic disc cupping after glaucoma surgery analyzed with a scanning laser tomograph. Ophthalmology 1999; 106: 1013-1018.

8 Irak I, Zangwill L, Garden V, Shakiba S, Weinreb RN. Change in optic disk topography after trabeculectomy. Am J Ophthalmol 1996; 122: 690-695.

9 Bowd C, Weinreb RN, Lee B, Emdadi A, Zangwill LM. Optic disk topography after medical treatment to reduce intraocular pressure. Am J Ophthalmol 2000; 130: 280-286.

10 Paranhos Jr A, Lima MC, Salim S, Caprioli J, Shields MB Trabeculectomy and optic nerve head topography. Braz J Med Biol Res 2006; 39: 149-155.

11 Meredith SP, Swift L, Eke T, Broadway DC. The acute morphologic changes that occur at the optic nerve head induced by medical reduction of intraocular pressure. J Glaucoma 2007; 16: 556-561.

12 Tan JC, Hitchings RA. Reversal of disc cupping after intraocular pressure reduction in topographic image series. I Glaucoma 2004; 13: 351-355.

13 Wells AP, Garway-Heath DF, Poostchi A, Wong T, Chan KC, Sachdev N. Corneal hysteresis but not corneal thickness correlates with optic nerve surface compliance in glaucoma patients. Invest Ophthalmol Vis Sci 2008; 49: 3262-3268.

14 Leske MC, Heijl A, Hyman L, Bengtsson B, Dong L, Yang $\mathrm{Z}$ et al. Predictors of long-term progression in the early manifest glaucoma trial. Ophthalmology 2007; 114: 1965-1972.

15 Nouri-Mahdavi K, Hoffman D, Coleman AL, Liu G, Li G, Gaasterland $\mathrm{D}$ et al. Predictive factors for glaucomatous visual field progression in the Advanced Glaucoma Intervention Study. Ophthalmology 2004; 111: 1627-1635.
16 Miglior S, Torri V, Zeyen T, Pfeiffer N, Vaz JC, Adamsons I et al. Intercurrent factors associated with the development of open-angle glaucoma in the European Glaucoma Prevention Study. Am J Ophthalmol 2007; 144: 266-275.

17 Congdon NG, Broman AT, Bandeen-Roche K, Grover D, Quigley HA. Central corneal thickness and corneal hysteresis associated with glaucoma damage. Am J Ophthalmol 2006; 141: 868-875.

18 de Voogd S, Ikram MK, Wolfs RC, Jansonius NM, Witteman JC, Hofman A et al. Is diabetes mellitus a risk factor for open-angle glaucoma? The Rotterdam Study. Ophthalmology 2006; 113: 1827-1831.

19 Musch DC, Gillespie BW, Lichter PR, Niziol LM, Janz NK, CIGTS Study Investigators. Visual field progression in the Collaborative Initial Glaucoma Treatment Study the impact of treatment and other baseline factors. Ophthalmology 2009; 116: 200-207.

20 AGIS Investigators. The Advanced Glaucoma Intervention Study (AGIS): 12. Baseline risk factors for sustained loss of visual field and visual acuity in patients with advanced glaucoma. Am J Ophthalmol 2002; 134: 499-512.

21 Chopra V, Varma R, Francis BA, Wu J, Torres M, Azen SP, Los Angeles Latino Eye Study Group. Type 2 diabetes mellitus and the risk of open-angle glaucoma the Los Angeles Latino Eye Study. Ophthalmology 2008; 115: 227-232.

22 Sigal IA, Flanagan JG, Tertinegg I, Ethier CR. Finite element modeling of optic nerve head biomechanics. Invest Ophthalmol Vis Sci 2004; 45: 4378-4387.

23 Sigal IA, Flanagan JG, Tertinegg I, Ethier CR. Modeling individual-specific human optic nerve head biomechanics. Part II: influence of material properties. Biomech Model Mechanobiol 2009; 8: 99-109.

24 Yang H, Downs JC, Girkin C, Sakata L, Bellezza A, Thompson $\mathrm{H}$ et al. 3-D histomorphometry of the normal and early glaucomatous monkey optic nerve head: lamina cribrosa and peripapillary scleral position and thickness. Invest Ophthalmol Vis Sci 2007; 48: 4597-4607.

25 Sigal IA, Flanagan JG, Tertinegg I, Ethier CR. Modeling individual-specific human optic nerve head biomechanics. Part I: IOP-induced deformations and influence of geometry. Biomech Model Mechanobiol 2009; 8: 85-98.

26 Sigal IA, Ethier CR. Biomechanics of the optic nerve head. Exp Eye Res 2009; 88: 799-807.

27 Hernandez MR, Luo XX, Andrzejewska W, Neufeld AH. Age-related changes in the extracellular matrix of the human optic nerve head. Am J Ophthalmol 1989; 107: 476-484.

28 Albon J, Karwatowski WS, Easty DL, Sims TJ, Duance VC. Age related changes in the non-collagenous components of the extracellular matrix of the human lamina cribrosa. $\mathrm{Br} \mathrm{J}$ Ophthalmol 2000; 84: 311-317.

29 Burgoyne CF, Downs JC. Premise and prediction-how optic nerve head biomechanics underlies the susceptibility and clinical behavior of the aged optic nerve head. J Glaucoma 2008; 17: 318-328.

30 Morrison JC, Johnson EC, Cepurna W, Jia L. Understanding mechanisms of pressure-induced optic nerve damage. Prog Retin Eye Res 2005; 24: 217-240.

31 Morrison JC, Dorman-Pease ME, Dunkelberger GR, Quigley HA. Optic nerve head extracellular matrix in primary optic atrophy and experimental glaucoma. Arch Ophthalmol 1990; 108: 1020-1024. 
32 Johnson EC, Morrison JC, Farrell S, Deppmeier L, Moore CG, McGinty MR et al. The effect of chronically elevated intraocular pressure on the rat optic nerve head extracellular matrix. Exp Eye Res 1996; 62: 663-674.

33 Brubaker RF. Delayed functional loss in glaucoma. LII Edward Jackson Memorial Lecture. Am J Ophthalmol 1996; 121: $473-483$.

34 Bellezza AJ, Hart RT, Burgoyne CF. The optic nerve head as a biomechanical structure: initial finite element modeling. Invest Ophthalmol Vis Sci 2000; 41: 2991-3000.

35 Lesk MR, Hafez AS, Descovich D. Relationship between central corneal thickness and changes of optic nerve head topography and blood flow after intraocular pressure reduction in open-angle glaucoma and ocular hypertension. Arch Ophthalmol 2006; 124: 1568-1572.

36 Bochmann F, Ang GS, Azuara-Blanco A. Lower corneal hysteresis in glaucoma patients with acquired pit of the optic nerve (APON). Graefes Arch Clin Exp Ophthalmol 2008; 246: 735-738.

37 Goldich Y, Barkana Y, Gerber Y, Rasko A, Morad Y, Harstein M et al. Effect of diabetes mellitus on biomechanical parameters of the cornea. J Cataract Refract Surg 2009; 35: 715-719.

38 Quigley HA. Can diabetes be good for glaucoma? Why can't we believe our own eyes (or data)? Arch Ophthalmol 2009; 127: 227-229.

39 Prata TS, Sousa AK, Garcia Filho CA, Doi LM, Paranhos Jr A. Assessment of corneal biomechanical properties and intraocular pressure in patients with rheumatoid arthritis. Can J Ophthalmol 2009; 44: 602.

40 Luce DA. Determining in vivo biomechanical properties of the cornea with an ocular response analyzer. J Cataract Refract Surg 2005; 31: 156-162.

41 Shah S, Laiquzzaman M, Bhojwani R, Mantry S, Cunliffe I. Assessment of the biomechanical properties of the cornea with the ocular response analyzer in normal and keratoconic eyes. Invest Ophthalmol Vis Sci 2007; 48: 3026-3031.

42 Touboul D, Roberts C, Kérautret J, Garra C, Maurice-Tison S, Saubusse E et al. Correlations between corneal hysteresis, intraocular pressure, and corneal central pachymetry. J Cataract Refract Surg 2008; 34: 616-622.

43 Lim LS, Gazzard G, Chan YH, Fong A, Kotecha A, Sim EL et al. Cornea biomechanical characteristics and their correlates with refractive error in Singapore children. Invest Ophthalmol Vis Sci 2008; 49: 3852-3857.

44 Medeiros FA, Weinreb RN. Evaluation of the influence of corneal biomechanical properties on intraocular pressure measurements using the ocular response analyzer. J Glaucoma 2006; 15: 364-370.

45 Sigal IA, Yang H, Roberts MD, Grimm JL, Burgoyne CF, Downs JC. Finite element models predict a reduction of IOP-induced stresses in the lamina cribrosa during progression from normal to early experimental glaucoma. Invest Ophthalmol Vis Sci 2009; 50 ARVO E-Abstract 4888.

46 Yang H, Downs JC, Sigal IA, Roberts MD, Thompson H, Burgoyne CF. Deformation of the normal monkey optic nerve head connective tissue after acute IOP elevation within 3-D histomorphometric reconstructions. Invest Ophthalmol Vis Sci 2009; 50: 5785-5799.

47 Quigley HA, Hohman RM, Addicks EM, Massof RW, Green WR. Morphologic changes in the lamina cribrosa correlated with neural loss in open-angle glaucoma. Am J Ophthalmol 1983; 95: 673-691.

48 Hernandez MR, Andrzejewska WM, Neufeld AH. Changes in the extracellular matrix of the human optic nerve head in primary open-angle glaucoma. Am J Ophthalmol 1990; 109: 180-188.

49 Sady C, Khosrof S, Nagaraj R. Advanced Maillard reaction and crosslinking of corneal collagen in diabetes. Biochem Biophys Res Commun 1995; 214: 793-797.

50 Goh SY, Cooper ME. The role of advanced glycation end products in progression and complications of diabetes. I Clin Endocrinol Metab 2008; 93: 1143-1152.

51 Castro DP, Prata TS, Lima VC, Biteli LG, de Moraes CG, Paranhos Jr A. Corneal viscoelasticity differences between diabetic and non-diabetic glaucomatous patients. J Glaucoma 2010; 19: 341-343.

52 Thornton IL, Dupps WJ, Roy AS, Krueger RR. Biomechanical effects of intraocular pressure elevation on optic nerve/lamina cribrosa before and after peripapillary scleral collagen cross-linking. Invest Ophthalmol Vis Sci 2009; 50: $1227-1233$.

53 Maumenee AE. Causes of optic nerve damage in glaucoma: Robert N Shaffer lecture. Ophthalmology 1983; 90: 741-752.

54 Yablonski ME, Asamoto A. Basic sciences in clinical glaucoma: hypothesis concerning the pathophysiology of optic nerve damage in open angle glaucoma. J Glaucoma 1993; 2: 119-227.

55 Hayreh SS. Pathogenesis of cupping of the optic disc. Br J Ophthalmol 1974; 58: 863-876.

56 Hayreh SS. Pathogenesis of optic nerve head changes in glaucoma. Semin Ophthalmol 1986; 1: 1-13.

57 Downs JC, Roberts MD, Burgoyne CF. Mechanical environment of the optic nerve head in glaucoma. Optom Vis Sci 2008; 85: 425-435.

58 Sigal IA, Flanagan JG, Ethier CR. Factors influencing optic nerve head biomechanics. Invest Ophthalmol Vis Sci 2005; 46: 4189-4199.

59 Sigal IA. Interactions between geometry and mechanical properties on the optic nerve head. Invest Ophthalmol Vis Sci 2009; 50: 2785-2795.

60 Greenfield DS, Weinreb RN. Role of optic nerve imaging in glaucoma clinical practice and clinical trials. Am J Ophthalmol 2008; 145: 598-603. 